\title{
Guerrero Aguirre, Francisco Javier, El voto de los mexicanos en el extranjero: antecedentes, reflexiones y una mirada hacia el futuro, México, Instituto Federal Electoral, 2013
}

Para todos los que hemos estado involucrados en la implementación y estudio del voto de los mexicanos residentes en el extranjero (VMRE), esta modalidad de voto ha sido motivo de gran frustración, derivada de un esquema que permite que nuestros conciudadanos voten desde el extranjero, pero que es tan exigente y complicado en sus requisitos que únicamente votan un puñado de los posibles electores.

El Instituto Federal Electoral (IFE) ha tenido la difícil tarea de ser la cara visible de un modelo, considerado como un timo hacia la comunidad migrante, quienes - junto a los medios de comunicación-que exigen más facilidades para votar y más votos desde el extranjero. El IFE debe justificar un modelo caro, poco eficaz y eficiente, que garantiza una pobre participación y que debe hacer suyo, pero que en realidad no es de su creación.

Frente a esta problemática Francisco Guerrero adoptó la postura de convertirse en un activista en pro de los derechos políticos de los migrantes. Ha sido un duro crítico del modelo a pesar de presidir la comisión interna del IFE encargada de su implementación. Su último libro presentado es más que un recuento de lo vivido en 2011 y 2012 en la promoción, y etapa de resultados del VMRE. Es un texto propositivo, informativo y crítico. 
La obra de Guerrero es lectura obligada para cualquier interesado en los derechos políticos de los mexicanos en el extranjero, en el fenómeno migratorio, en las condiciones de nuestros connacionales afuera y en el trato que les damos desde México. Guerrero adopta una visión multidisciplinaria a un problema multifacético. Lo anterior es la mayor virtud que tiene la obra. Este libro no es sólo útil para "electoreros" o "votólogos", es un texto de relevancia amplia para abogados, economistas, sociólogos, historiadores e internacionalistas.

\section{El fenómeno migratorio}

Guerrero inicia su libro abordando el fenómeno migratorio. No lo hace sólo desde la perspectiva electoral, sino también internacionalista y sociológica. Presenta cifras llamativas como sería que 4 de cada 10 de los migrantes latinoamericanos y caribeños son mexicanos.

Su análisis es exhaustivo, y describe el fenómeno migratorio como lo que es, mutable, cambiante, vivo. En México esto ha sido fácil de medir, los flujos migratorios han cambiado de los setenta y ochenta a la actualidad, también el perfil del migrante es distinto. El 11\% de nuestra población vive en los Estados Unidos de América, la cual constituye el $18 \%$ de nuestra fuerza laboral.

Guerrero hace una reflexión interesante en el capítulo, relaciona la expansión de la democracia con el aumento de la migración. Quizás esto se deba al estrecho vínculo que existe entre democracia y derechos humanos. Otra opción puede ser que las causas de la migración ya no son políticas como en décadas pasadas sino más bien relacionadas a la gran brecha económica que existe entre países del sur y del norte. La hipótesis es interesante.

A continuación el autor hace un recuento de la diáspora mexicana desde varias perspectivas. La geográfica hace referencia al origen de los mexicanos que deciden salir del país en buscan de más y mejores oportunidades y a dónde llegan. Relata cómo en un principio los estados expulsores eran Guanajuato, Jalisco, Michoacán, San Luis Potosí y Zacatecas. Más adelante inició la migración de estados como Guerrero, Puebla, Oaxaca, Hidalgo y Veracruz. Actualmente la mayoría de los estados cuenta con un número importante de originarios en el extranjero. El destino también ha cambiado así como el perfil ocupacional del migrante, originariamente el sector predominante era el agrícola, ahora es en la industria de los servicios. La migración no sólo 
se concentra en el suroeste de Estados Unidos sino en todo el país, inclusive llegando a Canadá.

Posteriormente Guerrero hace un análisis de la crisis financiera y su impacto en la migración y termina el capítulo con un avance de lo que seguirá en los siguientes capítulos: la dimensión política de la migración en México.

\section{Panorama del sufragio en el exterior}

En este capítulo Guerrero Aguirre aborda en términos generales la evolución del voto desde el extranjero. La interrogante que busca responder en estas páginas es ¿quién exactamente tiene el derecho a ser representado, y de qué manera?

Inicia con una discusión clara y amplia sobre ciudadanía y nacionalidad. Usando ejemplos comparados y sin enfrascarse en una discusión teórica interminable, Guerrero llega a la conclusión que ambos son conceptos soberanos que varían tanto geográficamente como por época. Aunque la obra trata del voto a distancia de los mexicanos, Guerrero no omite enfrentar una discusión igualmente importante, el voto de los mexicanos en su país de residencia. Para muchos mexicanos que viven en Estados Unidos, la oportunidad de votar en las elecciones norteamericanas reviste una mayor importancia que votar en las mexicanas.

En la página 23 menciona lo siguiente: "El reconocimiento del derecho al voto es una prerrogativa para la posterior integración social del inmigrante y no al revés, ${ }^{1}$ es decir, no se debe establecer el derecho al voto como premio o retribución a la integración, sino como un medio para alcanzarla. Los principios básicos de la democracia liberal exigen que aquellos que contribuyen a una sociedad y viven bajo sus leyes, participen en la toma de decisiones de la misma. Para los migrantes de hoy, estos principios son relevantes en la comunidad a la que llegan y en aquella que dejan, porque pueden mantener vínculos significativos con ambas".

La visión es idílica y poco probable, que un migrante pueda votar en todas las elecciones con las que tiene el vínculo de ciudadanía o residencia. Sin embargo obedece a una lógica congruente con la visión

1 González, Noelia, La desnacionalización de la ciudadanía: El derecho al voto de los extranjeros como requisito para la integración social, España, CSIC, 2007. 
occidental de los derechos fundamentales e inclusive con la visión norteamericana que dio origen a la independencia de Estados Unidos, "no taxation without representation". Los mexicanos que viven en el extranjero y envían remesas pagan impuestos en los dos países, por lo menos pagan el impuesto al consumo. Esta obligación debiera derivar en algún derecho, el voto es un buen inicio.

Guerrero luego explica los distintos modelos de voto a distancia, presencial, en consulados, electrónico, correo, fax, delegación de poder, etcétera. Escoge algunos ejemplos emblemáticos como España, Colombia y República Dominicana. De estos y muchos otros casos podemos concluir que con excepción de Australia, Italia y algunos países en donde el voto es obligatorio y su no ejercicio implica una sanción, el voto a distancia debe ser visto simplemente como un derecho que el país expulsor le otorga a sus ciudadanos en el exterior. Debemos de aceptar que no es comparable en costos ni en índices de participación con la votación que se lleva a cabo en el territorio nacional. La votación en el extranjero es una especie distinta de ejercicio democrático y debe ser valorado comparativamente consigo misma. En ese sentido las recomendaciones que hace Guerrero al final de su obra revisten un inmenso valor para mejorar el modelo actual.

\section{La implementación del voto fuera de México}

En el tercer capítulo de su obra, Guerrero hace un recuento histórico de los orígenes del voto de los mexicanos en el extranjero. Relata las reformas y las negociaciones que se llevaron a cabo así como los resultados de la primera experiencia del voto desde el extranjero en 2006.

El repaso histórico resalta los puntos más importantes lo cual tiene valor en sí mismo, pero lo más valioso es que Guerrero participó en el proceso de reforma al Cofipe como coordinador de asesores del presidente del Senado en aquel entonces. En dicha calidad, el autor fue testigo de las discusiones, de los miedos y de las conclusiones a las que llegaron los partidos políticos que permitieron que los mexicanos residentes en el extranjero pudieran votar.

Guerrero no duda en afirmar que - al final- los partidos no tuvieron más opción que reglamentar el derecho, ya que sería políticamente incorrecto no hacerlo, la presión era grande entre los propios partidos y de la comunidad en el extranjero. Sin embargo, la reglamentación dejó mucho que desear. 
En este capítulo Guerrero también describe los trabajos de la primera Comisión de Especialistas sobre Voto en el Extranjero que creó el IFE en 1998. Los 13 expertos trabajaron por seis meses y determinaron que era viable la votación de los mexicanos residentes en el extranjero y propusieron una serie de modelos de votación y de registro. Lo más significativo de este antecedente fue que los especialistas empezaron de la nada y decidieron presentar un abanico de posibilidades. En parte, esto se debió a que no existían grandes consensos en el grupo, además quisieron dejar la puerta abierta para que los legisladores tomaran las decisiones.

\section{El voto en el exterior en la elección de 2012}

A continuación Guerrero hace un recuento del proceso de implementación del voto en el extranjero durante 2011 y 2012. El resumen es valioso e inclusive sirve al lector en caso de que quiera posteriormente buscar referencias más específicas en el informe final que presentó la Comisión del Voto de los Mexicanos Residentes en el Extranjero. Guerrero describe bien el paso a paso de la función institucional que se requiere para la organización del voto en el exterior. Aunque en ningún momento lo dice, parecería que con la mera descripción de una tarea tan titánica buscará satirizar el proceso.

Asimismo, describe el Plan Estratégico y las actividades de la Comisión del Voto de los Mexicanos en el Extranjero, de la cual fue integrante, para posteriormente presidirla.

De estas páginas, lo más disfrutable es la experiencia vivencial del consejero Guerrero en las giras de trabajo, entrevistas y en el contacto humano con los mexicanos en el exterior.

No haré un recuento de todos los pasos y los datos precisos que comprenden estas páginas, pero sí haré alusión a algunos aspectos que me parecen importantes resaltar.

El IFE tomó varias decisiones excelentes en este ejercicio del voto de los mexicanos residentes en el extranjero, ello en relación con la experiencia del VMRE en 2006. La primera fue el porte pagado para que el envío de la solicitud por correo certificado no le costara al ciudadano. La segunda fue la omisión del comprobante de domicilio nacional que deben adjuntar a la solicitud para que sea procesada. La última -en mi opinión - fue permitir que las credenciales 03 pudieran seguir votando desde el extranjero. Sin embargo, a pesar de estos tres cambios 
Esta revista forma parte del acervo de la Biblioteca Jurídica Virtual del Instituto de Investigaciones Jurídicas de la UNAM

no menores y que claramente hubo una política por parte del IFE de favorecer a los ciudadanos en el extranjero, los resultados siguieron siendo raquíticos.

Si pudiera hacerle una crítica al texto tan cuidado de Guerrero, diría que usaron la experiencia de 2006 para justificar los resultados de 2012. Entiendo que éste fue un discurso institucional del IFE, el cual también se ve reflejado en las páginas del libro de Guerrero. Hay varias razones por las que difiero de esta estrategia. La primera es que aunque los integrantes del Consejo General del IFE cambien, el IFE tiene memoria institucional y los avances deben de medirse como evolución y aprendizaje, no como crítica al pasado. Segundo, si bien en esta ocasión se hizo una mejor planeación y ahorro, la realidad es que el IFE tuvo seis años para planear y economizar, en 2006 tuvo apenas un año para organizar la elección y dar a conocer el nuevo modelo de votación. Por último, el argumento de que recibieron más votos y costó menos dinero es un discurso conformista. También se puede argumentar que disminuyó el porcentaje de la relación de participación entre inscritos y votos emitidos o que la participación en Estados Unidos disminuyó. Lo pernicioso para una institución es hacer esas comparaciones para justificar una función. A mí me queda claro, como testigo de ambos procesos, que el IFE puso todo su empeño en las dos ocasiones para que fueran experiencias exitosas. También tengo certeza de que lo que se debe corregir es el modelo.

En este sentido Guerrero hace también alusión a la experiencia del voto de los ciudadanos del Distrito Federal en el extranjero (voto chilango) que combina la modalidad postal con el voto por Internet. Sin duda, el voto chilango ha sido la experiencia más exitosa a nivel local en México. Guerrero no sólo describe el proceso en el Distrito Federal sino que lo valora y compara con la experiencia federal.

Por último, Guerrero hace referencia a lo duro que fue enfrentarse a los medios de comunicación y a la población mexicana en el extranjero con el presente mecanismo para votar. Para calmar los ánimos el IFE realizó dos foros académicos y políticos en Estados Unidos con representantes de partidos políticos nacionales. De estos foros salió el Compromiso de Chicago, que básicamente implica que los partidos aprueben en el Congreso las modificaciones legales que permita al IFE credencializar en el extranjero y se exploren nuevas modalidades de votación. 
Los siguientes dos capítulos se refieren a las acciones que encaminó el IFE posteriores a la elección. El IFE encargó al Centro de Investigación y Docencia Económicas (CIDE) una serie de encuestas en algunos consulados de México en el exterior para conocer opiniones de los mexicanos el extranjero. Entre los datos reveladores, el $85 \%$ de los encuestados mostraron disposición de renovar su credencial en México en caso de poder regresar y la misma cantidad se mostró interesada en poder tramitar su credencial en los consulados, más del 50\% considera que es un instrumento de identificación importante, pero sólo el $10.6 \%$ conocía los trámites necesarios para poder votar desde el extranjero.

El siguiente estudio que realizó el IFE fue una valoración jurídica del Libro Sexto del Cofipe. Tuve la fortuna de colaborar en este estudio que fue coordinado por el doctor César Astudillo Reyes del Instituto de Investigaciones Jurídicas de la UNAM. El análisis llega a la conclusión tajante que en el modelo actual de VMRE se contiene una serie de restricciones que no favorecen el ejercicio del voto desde el extranjero.

El IFE también ordenó la elaboración de un Libro Blanco del Voto de los Mexicanos Residentes en el Extranjero que terminó siendo de 12 tomos. Por último, en parte por la gran insistencia del consejero Guerrero, el IFE ordenó la creación de un Comité Técnico de Especialistas sobre VMRE que yo tuve el privilegio de coordinar. Dicho comité trabajó durante cinco meses para elaborar una propuesta técnica, jurídica y presupuestal que sea una alternativa viable al modelo actual de votación desde el extranjero. La propuesta fue aprobada por el Consejo General del IFE en julio y propone credencializar en el extranjero y adoptar como modelo único de voto por Internet.

Considero que las acciones antes descritas forman parte de un expediente y una ruta hacia un cambio de modelo con todos los elementos necesarios. Primero, la evaluación del modelo actual, tanto interno como externo, sociológico como jurídico, segundo, una propuesta elaborada por expertos independientes conocedores de la materia que contiene no sólo los aspectos técnicos sino la propuesta de modificación legal. 


\section{Conclusiones}

En las reflexiones finales Guerrero reitera su desacuerdo con el actual modelo, pero también hace una serie de recomendaciones (muchas de ellas coinciden con las de los expertos del Comité).

Entre ellas Guerrero propone alejarse del modelo postal, que el IFE pueda credencializar en el extranjero, sugiere un modelo de votación mixto, presencial en algunas ciudades y por Internet en otros. Propone la eliminación de la restricción de hacer campañas en el extranjero. También considera que es importante que el listado nominal de electores en el extranjero no sea temporal sino permanente. El ajuste de tiempos es fundamental para Guerrero, ya que los ciudadanos deben inscribirse antes de conocer a los candidatos y votar con gran anticipación al día de la jornada. El IFE debe contar con una estructura permanente que vincule a la institución con la población mexicana en el exterior. La promoción del voto en el extranjero también debe de ser una función permanente del IFE. Sugiere la posibilidad del voto pasivo desde el extranjero para diputados a través de una sexta circunscripción y por último el voto activo para residentes extranjeros en México.

Aunque creo que algunas de las propuestas de Guerrero son a largo plazo, coincido con todas y creo que el paso de los años le dará la razón. En realidad hacia allá va la globalización de los derechos políticos. Termino esta reseña de la forma que la empecé, recomendando ampliamente el libro de Francisco Guerrero.

\section{Gerardo de Icaza Hernández Consultor en materia electoral}

